\title{
La duquesa y Altisidora: dos enemigas de Dulcinea
}

\section{The Duchess and Altisidora: Two Enemies of Dulcinea}

\author{
Amalia Iriarte \\ Universidad de Los Andes \\ COLOMBIA \\ airiarte@uniandes.edu.co
}

[Hipogrifo, (issn: 2328-1308), 3.2, 2015, pp. 253-261]

Recibido: 24-03-2015/ Aceptado: 03-05-2015

DOI: http://dx.doi.org/10.13035/H.2015.03.02.16

Resumen. A partir del recuerdo de Aldonza Lorenzo, don Quijote crea a Dulcinea del Toboso, la amada del caballero andante. Este personaje se va alejando de la muchacha campesina que inspiró a su creador, hasta hacerla desaparecer definitivamente, mientras la imaginaria Dulcinea, instalada en el mundo interior del hidalgo manchego, va cobrando fuerza hasta abrirse un espacio considerable en la novela y una influencia en el desarrollo de sus acontecimientos. Esto se hará muy evidente en la segunda parte de la novela, pues en la corte de los duques hay dos damas, la duquesa y Altisidora que asumen la tarea de menoscabar a Dulcinea, evidenciar su inexistencia, y suplantarla en los sentimientos del caballero por una enamorada de carne y hueso, papel que asumirá Altisidora. En el presente ensayo pretendo mostrar cómo entre más golpes recibe Dulcinea de parte de estas damas reales, la amada imaginaria se hace más fuerte en el alma del caballero. Este proceso se enmarca en uno de los conflictos centrales de la novela de Cervantes: el combate que se libra entre los seres creados por la imaginación y aquellos que admitimos como reales.

Palabras clave. Don Quijote, mundo real, mundo imaginario.

Abstract. Don Quixote creates Dulcinea of El Toboso, the beloved of the knight-errant, out of his recollections of Aldonza Lorenzo. The character of Dulcinea is very different from the peasant woman who inspired her creation, to the point that the latter is entirely effaced, while the imaginary Dulcinea, as she has taken possession of don Quixote's inner world, becomes stronger and plays an increasingly important role in the novel, exerting influence on the development of events. This will be more evident in the second part of the novel, where two women at the duke's court, the 
duchess herself and Altisidora, take on the task of unmasking the nonexistence of Dulcinea, and induce don Quixote to fall in love with a real woman, a role assumed by Altisidora. In this essay, I argue that the more these real women question Dulcinea, the stronger will be don Quixote's feelings for his imaginary beloved. This process takes place within one of the central conflicts of Cervantes' novel: the struggle between the creatures of the imagination and those we accept as real.

Keywords. Don Quixote, Real World, Imaginary World.

Entre las muchas y variadas figuras femeninas que circulan por las páginas del Quijote, la más impactante es Dulcinea del Toboso, «uno de los personajes de concepción más extraordinaria de la literatura», ante todo porque, su identidad, su existencia, «su estatus ontológico» son ambiguos y problemáticos ${ }^{7}$. En palabras de Manuel Durán, el Quijote es quizás la única novela importante, una de cuyas figuras centrales, Dulcinea, «ni siquiera existe en el sentido corriente de la palabra»?2. «No es en el mundo, sino que es dama fantástica», dirá de ella un personaje muy destacado en la obra $(\mathrm{II}, 32)^{3}$.

En el texto la mujer de más alta jerarquía social es la duquesa, una de cuyas damas de compañía, Altisidora, joven bella y audaz, goza de su entera confianza. La relación socarrona que ellas establecen con la forma de amar de don Quijote, contribuye a dar dimensiones protagónicas a Dulcinea, que se sitúa entonces, en el centro mismo de uno de los grandes conflictos de la novela: la lucha entre lo real y lo imaginario; además, hace evidente la fuerza de la vida interior del hidalgo manchego y la firmeza de su fe en el mundo que ha inventado. Es que en la novela de Cervantes someter a burlas el mundo imaginario - así como quemar libros de caballerías- es vigorizarlo. Este hecho, la disputa entre los entes creados por la imaginación y aquellos que denominamos reales, abre uno de los campos de reflexión más complejos y trascendentales del texto cervantino.

A pesar de la broma de rústica brutalidad que le gastan a don Quijote las mujeres de la venta de Palomeque en el capítulo 43 de la Primera Parte, la mayoría de los personajes femeninos de la novela carece de malicia: o bien tratan de ayudar a curarlo, como el ama y la sobrina, o le siguen la cuerda para llevarlo de regreso a casa, como Dorotea, o le piden sinceramente ayuda, como doña Rodríguez. Sólo en la duquesa y Altisidora hay muestras de mala intención hacia al caballero y esto, casi siempre, a costa de su amada. Pero a medida que las bromas se hacen ácidas y agresivas, Dulcinea va tomando fuerza: «alcanza su mayor importancia en la segunda parte de la novela - dice Manuel Durán-. Y cuando más influye en don Quijote es precisamente cuando más en duda se halla su esencia» ${ }^{4}$.

Al final del primer capítulo, después de alistar las armas, poner nombre a su caballo y ponérselo a sí mismo, entra Dulcinea en escena como el último de los

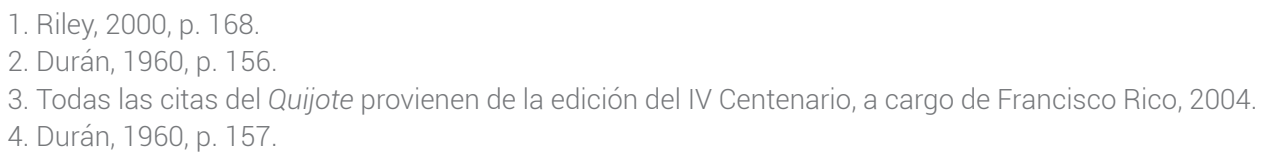


adminículos que requiere el caballero errante, «casi como un añadido tardío a los preparativos de don Quijote para iniciar su carrera» dice Riley ${ }^{5}$. Y es que, en palabras del propio manchego, «no puede ser que haya caballero andante sin dama», y en caso de estar sin amores «no sería tenido por legítimo caballero» $(I, 13)$.

En sus primeras apariciones, Dulcinea muestra un carácter convencional y su evocación obedece más a un modelo libresco que a un sentimiento, una emoción. Por ejemplo, a propósito del soliloquio del hidalgo, en el capítulo 2, comenta el narrador: «diciendo como si verdaderamente fuera enamorado». En su primera aventura $(I, 4)$ exige a unos mercaderes, luego de transformarlos en caballeros andantes, que reconozcan la superior belleza de «la emperatriz de la Mancha»; en los capítulos 8 y 22 de la Primera Parte, don Quijote pretende que se presenten ante Dulcinea el vizcaíno vencido y los galeotes liberados. Actos como éstos son fórmulas de comportamiento en los libros de caballerías; también lo es resistirse, por lealtad a su dama, al asedio femenino que en los castillos sufren los caballeros andantes. Así actúa don Quijote en la venta de Palomeque al resistirse al supuesto asedio de una «fermosa doncella», es decir Maritornes en el capítulo 16, y también al desdeñar la posibilidad de casarse con la princesa Micomicona, es decir Dorotea, en el 30.

Donde la relación del hidalgo con Dulcinea empieza a salirse del modelo consagrado en los libros de caballerías y a adquirir textura y complejidad es, ya mediando la Primera Parte, en la Sierra Morena (I, 25), cuando don Quijote, al decidirse a enviar a Sancho al Toboso, somete su creación a la dura prueba de la realidad. Es entonces cuando, por última vez, se hace explícita una relación entre Aldonza Lorenzo y Dulcinea:

- [...] en doce años que ha que la quiero [...] no la he visto cuatro veces, - aclara don Quijote a Sancho- y aun podrá ser que destas cuatro veces no hubiese ella echado de ver la una que la miraba; tal es el recato y encerramiento con que sus padres Lorenzo Corchuelo y su madre Aldonza Nogales la han criado.

- [...] ¿la hija de Lorenzo Corchuelo es la señora Dulcinea del Toboso, llamada por otro nombre Aldonza Lorenzo? - pregunta Sancho.

- Esa es -dijo Don Quijote-y es la que merece ser señora de todo el universo.

Una vez se revela la identidad de Dulcinea, Sancho afirma conocerla y procede a hacer hace una semblanza de Aldonza Lorenzo, la única que tenemos, con detalles como éste:

[...] sé decir que tira tan bien una barra como el más forzudo zagal. [...]. Se puso un día encima del campanario de la aldea a llamar unos zagales [...] y aunque estaban de allí más de media legua, así la oyeron como si estuvieran al pie de la torre; [...] con todos se burla, y de todo hace mueca y donaire.

Y termina así su semblanza de la aldeana: 
Ahora digo, señor Caballero de la Triste Figura, que no solamente puede y debe vuestra merced hacer locuras por ella [...]. Y confieso [...] que hasta aquí he estado en una grande ignorancia, que pensaba [...] que la señora Dulcinea debía de ser alguna princesa de quien vuestra merced estaba enamorado [...].

Don Quijote no rechaza esta imagen campechana de su amada; incluso parece darle fundamento a su elección en términos que remiten a la tradición del amor cortés:

Por lo que yo quiero a Dulcinea del Toboso, tanto vale como la más alta princesa de la tierra. Sí, que no todos los poetas que alaban damas debajo de un nombre que ellos a su albedrío les ponen, es verdad que las tienen. ¿Piensas tú que las Amarilis, las Filis, las Silvias [...] fueron verdaderamente damas de carne y hueso [...]? Las más se las finge por dar sujeto a sus versos, y porque los tengan por enamorados [...]: y así bástame a mí pensar y creer que la buena de Aldonza Lorenzo es hermosa y honesta, [...] y yo me hago cuenta que es la más alta princesa del mundo, [...] y para concluir con todo, yo me imagino que todo lo que digo es así [...] y píntola en mi imaginación como la deseo.

En adelante Aldonza desaparece tras la sin par Dulcinea. Cuando Sancho regresa a la sierra de su simulada embajada al Toboso, aunque la sitúa en un mundo rural, desempeñando trabajos agrícolas, se refiere a ella como «mi señora Dulcinea» y acepta la traducción que va haciendo don Quijote de lo campesino a lo cortesano, de los granos de trigo a los granos de perlas (I, 30 y 31$)$.

Pero es en la Segunda Parte donde Dulcinea se convierte en figura central, donde trasciende el libreto pre establecido de dama de caballero andante. Al instalarse en el mundo interior del manchego la naturaleza de este personaje se vuelve más y más compleja y donde se somete a prueba su existencia. Sin embargo, sale airosa.

Ante todo, hay que destacar que a partir de la visita al Toboso (II, 9) se manifiestan en don Quijote una vida interior y unos complejos estados de ánimo, antes reducidos a esporádicas rabietas. El desconcierto, la desazón, empiezan a manifestarse ya en los umbrales de «la gran ciudad del Toboso», a donde caballero y escudero llegan a medianoche, entre ruidos desapacibles y cantos agoreros. Las alteraciones del ánimo quijotesco están, por lo tanto, estrechamente relacionadas con Dulcinea, cuya entidad se va haciendo más y más problemática, empezando por este diálogo entre caballero y escudero:

- ¿No te he dicho mil veces que en todos los días de mi vida no he visto a la sin par Dulcinea, ni jamás atravesé los umbrales de su palacio, y que sólo estoy enamorado de oídas y de la gran fama que tiene de hermosa y discreta?

- [...] digo que -respondió Sancho- pues vuestra merced no la ha visto, ni yo tampoco...

A la entrada del Toboso Sancho nota a su amo «suspenso» y «asaz mal contento» (II, 9) porque es él, dice Auerbach, «quien nos ayuda mejor que nadie a comprender a don Quijote». Es más: nadie experimenta su personalidad «de un modo 
tan completo, nadie se la asimila directamente y como un todo con tanta pureza como Sancho» ${ }^{6}$.

Cuando deciden que el escudero ingrese al poblado con el recado para Dulcinea, el caballero queda solitario, emboscado y lleno de temores, y es Sancho quien advierte que algo le sucede al amo: «ensanche vuestra merced, señor mío, ese corazoncillo, que le debe de tener agora no mayor que una avellana» (II, 9). Pero es la aparición de la dama encantada, convertida en ruda y grosera labriega, la que traerá la melancolía:

- Levántate, Sancho - dijo a este punto don Quijote-, que ya veo que la Fortuna, de mi mal no harta, tiene tomados los caminos todos por donde pueda venir algún contento a esta ánima mezquina que tengo en las carnes.

Expresiones como «yo nací para ejemplo de desdichados, y para ser blanco y terrero donde tomen la mira y asiesten las flechas de la mala fortuna» 0 «diré mil veces que soy el más desdichado de los hombres» se harán frecuentes, así como comentarios del narrador, como éste:

Pensativo además iba don Quijote por su camino adelante, considerando la mala burla que le habían hecho los encantadores volviendo a su señora Dulcinea en la mala figura de la aldeana [...] y estos pensamientos le llevaban tan fuera de sí, que sin sentirlo soltó las riendas a Rocinante (II, 11).

Pero también aparece la ahora creciente solidaridad de Sancho, encantador de Dulcinea y causante de las congojas de su amo:

Señor, las tristezas no se hicieron para las bestias, sino para los hombres, pero si los hombres las sienten demasiado, se vuelven bestias: vuestra merced [...] muestre aquella gallardía que conviene que tengan los caballeros andantes. [...] ¿Qué descaecimiento es este? [...] Mas que se lleve Satanás a cuantas Dulcineas hay en el mundo, pues vale más la salud de un solo caballero andante que todos los encantos y transformaciones de la tierra $(\mathrm{II}, 11)$.

Dulcinea, antes apostada en su aldea, como nos la presentó Sancho en la Sierra Morena (I, 25), ahora se instala en la imaginación de don Quijote: no encontraremos su casa en el Toboso, no la oiremos llamando a los zagales desde el campanario ni la veremos tirar bien una barra. La veremos, en cambio, o transformada en una pueblerina grotesca, o en la figura onírica que aparece en la cueva de Montesinos, imagen que emana de las profundidades de la conciencia de don Quijote (II, 23), o burdamente representada en el teatro ducal. A pesar de ello, seguirá presente y colmada de perfecciones en el corazón de su enamorado.

Falta ver si el manchego está preparado para el embate que la existencia de Dulcinea y su lealtad hacia ella sufrirán en la corte de los duques. Si sale airoso, será evidente la fuerza que ha ido adquiriendo la creatura en la imaginación de su creador.

6. Auerbach, 2000, p. 333 
Quienes auspiciaron e incluso protagonizaron buena parte de las burlas que se fraguaron en la corte contra el caballero y su escudero fueron, principalmente, la duquesa y Altisidora que no buscaban, en principio, más que divertirse a costa de fastidiar a sus huéspedes, de rebajarlos a la condición de bufones?.

No es casual que el blanco de las zumbas más ácidas haya sido Dulcinea, la creación más entrañable de don Quijote. La primera y quizás la más difícil de sortear no fue una broma sino una celada consistente en una observación de la duquesa, que se dio en el apacible ambiente de la sobremesa. Allí don Quijote, creyendo estar entre amigos, narró con toda sinceridad a sus anfitriones la peor de sus desdichas: el encantamiento de Dulcinea. Apoyada en su alto rango, en su buen conocimiento del recién publicado Quijote y haciendo gala de un prosaico sentido común, la duquesa enfrentó al caballero a la inexistencia de Dulcinea:

si hemos de dar crédito a la historia que del señor don Quijote de pocos días a esta parte ha salido a la luz del mundo, [...] della se colige, si mal no me acuerdo, que nunca vuesa merced ha visto a la señora Dulcinea, y que esta tal señora no es en el mundo, sino que es dama fantástica, que vuesa merced la engendró y parió en su entendimiento, y la pintó con todas aquellas gracias y perfecciones que quiso (II, 32).

La respuesta de don Quijote viene, como es de esperarse, de una zona muy ajena a la del sentido común, muy distante de la actitud práctica ante la vida y de la concepción utilitaria del mundo que guían a la duquesa:

- En eso hay mucho que decir [...]. Dios sabe si hay Dulcinea o no en el mundo, o si es fantástica o no es fantástica; y éstas no son de las cosas cuya averiguación se ha de llevar hasta el cabo. Ni yo engendré ni parí a mi señora, puesto que la contemplo como conviene que sea una dama que contenga en sí las partes que puedan hacerla famosa en todas las del mundo (II, 32).

Y es que Dulcinea habita en el territorio de la ambigüedad: en el hay o no hay, es fantástica o no lo es, en el de las cosas cuya averiguación no se ha de llevar a cabo, región en la que no existen certezas porque, recuerda Ángel del Río, si de algo se burla Cervantes es «especialmente, de toda pretensión de certeza»${ }^{\circledR}$. Es más: en este punto de la historia, don Quijote acepta que puede no haber Dulcinea, y que eso no lo afecta.

Los duques y su corte pasan, entonces, a poner en escena ante don Quijote un simulacro de su amada. Se trata de la poco convincente versión teatral de Dulcinea - un paje travestido- que, aunque es de una belleza tangible, de carne y hueso, hermosa como «una argentada ninfa», está dotada de una gruesa «VOz no muy adamada», y hace gala de desenfado varonil y de un vocabulario soez. Y así reprocha a Sancho que se resista a vapulearse por ella (II, 35): 
malaventurado

alma de cántaro

corazón de alcornoque, de entrañas apedernaladas

ladrón desuellacaras

enemigo del género humano,

miserable y endurecido animal

ojos de machuelo espantadizo

socarrón y malintencionado monstro

bestión indómito,

epítetos que Sancho recibe con un cierto dejo de ironía:

querría yo saber de la señora mi señora doña Dulcinea del Toboso adónde aprendió el modo de rogar que tiene: viene a pedirme que me abra las carnes a azotes, y llámame alma de cántaro y bestión indómito, con una tiramira de malos nombres, que el diablo los sufra.

La aparición de esta dama de comparsa no tiene en don Quijote los efectos que el director de escena, los espectadores y aún los lectores esperaban. Estos se reducen a comprobar, como dice el paje disfrazado para convencer a Sancho que acepte la azotaina, que su amo tiene el alma «atravesada en la garganta»; «como una nuez de ballesta», confirma don Quijote. Y eso es todo: en adelante, el caballero se referirá al episodio sólo para recordarle al escudero los azotes que tendría que darse para desencantar a la amada.

Como los dardos dirigidos contra la existencia de la dama y la presencia del simulacro teatral no dieron resultado, las grandes señoras cambian de estrategia: enfrentar a Dulcinea con hermosas mujeres reales.

Una vez que Sancho se va a la Ínsula, «don Quijote sintió su soledad» (II, 44); al percatarse la duquesa de la melancolía de su huésped le ofrece insistentemente poner a su servicio cuatro doncellas, «hermosas como unas flores», oferta que el hidalgo rechaza enérgicamente: «déjeme [...] que yo ponga una muralla en medio de mis deseos y de mi honestidad». Y es que don Quijote reconoce sus instintos, todavía muy vivos.

Como este ardid no tuvo el éxito esperado, tendrá que asumir la bella y audaz Altisidora, el papel de la doncella seductora, con el encargo de vencer al hidalgo cincuentón, treta que, consecuente con la visión práctica del mundo que la joven comparte con su señora, no podría fallar. Pero falla, a pesar de haber seguido el libreto establecido en los libros de caballerías, que Altisidora conoce muy bien: no valen sus serenatas, desmayos, requiebros, reproches, amenazas contra su rival Dulcinea. El manchego mantiene inquebrantable su lealtad.

Cuando Don Quijote sale, al fin, del palacete del duque está preparado para afrontar la prueba definitiva: disponerse a morir por su dama. Derrumbado en la playa de Barcelona, con la punta de la lanza del de la Blanca Luna sobre la visera, dice el caballero andante, «como si hablara dentro de una tumba»: 
Dulcinea del Toboso es la más hermosa mujer del mundo, y yo el más desdichado caballero de la tierra, y no es bien que mi flaqueza defraude esta verdad. Aprieta, caballero, la lanza, y quítame la vida, pues me has quitado la honra (II, 64).

El hombre de armas ha sido vencido, pero el amante ha salido airoso. No así Altisidora quien, protagonista en un último y aparatoso espectáculo farsesco montado en la «casa de placer» de los duques, es definitivamente derrotada por Dulcinea.

En efecto, de regreso a la aldea, capturados por anacrónicos guerreros, don Quijote y Sancho son devueltos a la corte ducal. Allí, en medio de histriones chabacanos disfrazados de dioses griegos, iluminado por «más de quinientas luminarias» aparece el túmulo de Altisidora, muerta de amor por el manchego. Es de notar que el narrador subraya el carácter mal fingido, mal simulado de la escena; tampoco don Quijote y Sancho parecen tomársela en serio. Se trata, de nuevo, de someter a Sancho a vejámenes, esta vez para resucitar a la doncella, lo que termina con un violento arrebato de dignidad del escudero y la broma no puede pasar adelante (II, 69).

La resucitada Altisidora agota recursos para poner en aprietos a don Quijote: ingresa a su habitación en la noche a dolerse de su desdén, que la han llevado a la muerte; pero sufre un nuevo y enfático rechazo, logrando así una victoria más la imaginaria Dulcinea sobre la muy real Altisidora:

- Yo nací para ser de Dulcinea del Toboso, [...] y pensar que otra alguna hermosura ha de ocupar el lugar que en mi alma tiene es pensar lo imposible.

Oyendo lo cual Altisidora, mostrando enojarse y alterarse, le dijo

- ¿Pensáis por ventura, don vencido y don molido a palos, que yo me he muerto por vos? Todo lo que habéis visto esta noche ha sido fingido; que no soy yo mujer que por semejantes camellos había de dejar que me doliese un negro de la uña, cuanto más morirme $(I I, 70)$.

Lesionada su autoestima, la actriz, no el personaje que venía representando, se despoja de su máscara, indignada por el efecto nulo que, contra toda previsión, su trabajo escénico y sus dotes de seductora han causado en don Quijote. No es así como reacciona una buena actriz, pero sí como actúa un auténtico caballero andante.

Como adversarias de la fantasía, la duquesa y Altisidora trataron de menoscabar la fe de don Quijote en su invención; al no lograrlo, pretendieron suplantarla por la presencia física de una mujer de carne y hueso. Tampoco lo lograron. Don Quijote, sereno y seguro, defendió, «hasta lo último - dice Pedro Salinas - lo que no se ha visto contra lo que se ve» ${ }^{9}$ y así la disputa que se libró en los campos de la Mancha, en el ducado aragonés, en las calles y playas de Barcelona entre el mundo de la imaginación y aquel que admitimos como real, Miguel de Cervantes la ha dejado abierta.

9. Salinas, 1958, p. 129 


\section{BIBLIOGRAFÍA}

Auerbach, Erich, Mímesis, la representación de la realidad en la literatura occidental, México, Fondo de Cultura Económica, 2011 [1942].

Cervantes, Miguel de, Don Quijote de la Mancha, ed. Francisco Rico, San Pablo, Alfaguara, 2004.

Del Río, Ángel, «El equívoco del Quijote», Hispanic Review, 27, 1959, pp. 200-221.

Durán, Manuel, La ambigüedad en el Quijote, Xalapa, Biblioteca de la Facultad de Filosofía y Letras, Universidad Veracruzana, 1960.

Martin, Adrienne L., «Humor and Violence in Cervantes», en The Cambridge Companion to Cervantes, ed. Anthony J. Cascardi, Cambridge, Cambridge University Press, 2002, pp. 160-185.

Riley, Edward C., Introducción al «Quijote», Barcelona, Crítica, 2000 [1986].

Salinas, Pedro, Ensayos de literatura hispánica. Del «Cantar de Mio Cid» a García Lorca, Madrid, Aguilar, 1958. 
